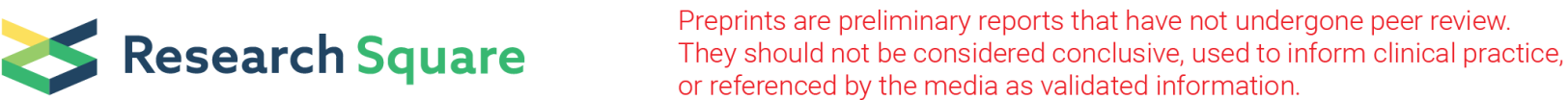

\section{Non-invasive ventilation as the initial ventilatory strategy in very old critically ill patients with community-acquired pneumonia: a multicenter cohort study}

Bruno Adler Maccagnan Pinheiro Besen ( $\sim$ brunobesen@yahoo.com.br)

Hospital das Clínicas HCFMUSP, Faculdade de Medicina, Universidade de São Paulo https://orcid.org/0000-0002-3516-9696

Marcelo Park

Medical ICU, Hospital das Clínicas HCFMUSP, Faculdade de Medicina, Universidade de São Paulo Otavio Tavares Ranzani

Pulmonary Division, Heart Institute (InCor), Hospital das Clínicas HCFMUSP, Faculdade de Medicina, Universidade de São Paulo

\section{Research article}

Keywords: Critical Care, Pneumonia, Non invasive ventilation, Very old patients

Posted Date: March 9th, 2020

DOI: https://doi.org/10.21203/rs.3.rs-16426/v1

License: (c) (1) This work is licensed under a Creative Commons Attribution 4.0 International License.

Read Full License 


\section{Abstract}

Background The very old patients ( $\geq 80$ years-old, VOP) comprise a subpopulation increasingly admitted to intensive care units (ICUs). Community-acquired pneumonia (CAP) is a common reason for admission and the best strategy of mechanical ventilation for respiratory failure in this scenario is not fully known.

Methods Multicenter cohort study of VOPs admitted with CAP in need of invasive (IMV) or noninvasive (NIV) mechanical ventilation to 11 Brazilian ICUs from 2009 through 2012. We used logistic regression models to evaluate the association between ventilator strategy (NIV vs. IMV) and hospital mortality adjusting for confounding factors. We evaluated effect modification with interaction terms in prespecified sub-groups.

Results Of 369 VOPs admitted for CAP with respiratory failure, 232 (63\%) received NIV and 137 (37\%) received IMV as initial ventilatory strategy. IMV patients were sicker at ICU admission (median SOFA 8 vs. $4, p<0.001)$. Hospital mortality was $114 / 232(49 \%)$ for NIV and $90 / 137(66 \%)$ for IMV. For the comparison NIV vs. IMV (reference), the crude odds ratio (OR) was 0.50 (95\% Cl, 0.33-0.78, p=0.002).

This association was largely confounded by antecedent characteristics and non-respiratory SOFA (adjOR $=0.70,95 \% \mathrm{Cl}, 0.41-1.20, \mathrm{p}=0.196)$. The fully adjusted model, including Pao2/Fio2 ratio, $\mathrm{pH}$ and Paco2, yielded an adjOR of $0.81(95 \% \mathrm{Cl}, 0.46-1.41, \mathrm{p}=0.452)$. There was no strong evidence of effect modification among relevant subgroups, such as Pao2/Fio2 ratio $\leq 150(p=0.30)$, acute respiratory acidosis $(p=0.42)$ and non-respiratory SOFA $\geq 4(p=0.53)$.

Conclusions NIV was not associated with lower hospital mortality when compared to IMV in critically ill VOP admitted with CAP, but there was no strong signal of harm from its use. The main confounders of this association were both the severity of respiratory dysfunction and of extra-respiratory organ failures.

\section{Background}

The very old patients ( $\geq 80$ years-old) (VOPs) are a subpopulation increasingly admitted to ICUs. Common reasons for admission among VOPs are respiratory diagnoses(1), especially pneumonia, for which the initial strategy of respiratory support is controversial: while non-invasive ventilation (NIV) may be an option (2), it carries a risk of failure of up to $50 \%$ in this scenario $(3,4)$, which is associated with worse outcomes (5). In contrast, invasive mechanical ventilation (IMV) also carries the risk of important adverse events that could impact both on mortality and on the functional outcome of the VOP.

The VOPs commonly have a high burden of comorbidities combined with impaired functional status $(1,6$, $7)$ and frailty $(1,8)$, which pose a special challenge for the clinician upon treatment decision-making. Indeed, VOP is prone to worse physiological abnormalities and higher risk of NIV failure (9). By contrast, chronic obstructive pulmonary disease (COPD) and congestive heart failure (CHF) are common comorbidities in VOP and known to benefit from NIV in acute respiratory failure $(2,10,11)$, possibly even in patients with pneumonia (2). 
The decision to provide organ support in VOPs involves more complex decision-making and may vary among intensivists (12). While the elderly are reluctant to accept IMV as a reasonable life sustaining therapy (13), NIV may still be considered a reasonable option as ceiling therapy without detrimental effects on quality of life (14). In this context, NIV in VOPs may allow for a less invasive strategy in a timelimited ICU trial (15), which could suffice for decision making throughout the course of ICU stay while not lending these patients subject to unnecessary suffering and potential harms from IMV.

However, data supporting the use of NIV in this subpopulation is scarce. Our objective was to evaluate the association between the initial ventilatory strategy of respiratory support - NIV or IMV - and hospital mortality in a representative sample of VOPs admitted to intensive care units with community-acquired pneumonia (CAP) as main reason of ICU admission. We hypothesized that a less invasive strategy of organ support could be beneficial in VOPs with pneumonia.

\section{Methods}

\section{Study design, setting and ethical considerations}

This is a multicenter retrospective cohort study between January, 2009 and December, 2012. There were 11 participating ICUs from a Brazilian network of private hospitals. One hospital is specialized in the care of heart diseases, while the others are mixed ICUs.

The Research and Ethics Committee of Hospital Pró-Cardíaco - the reference ethics committee designated by the National Research Ethics Committee - approved the retrospective analysis and publication of the data under the number 729.008 (CAAE: 33111214.3.0000.5533) and waived the need for informed consent. We adhered to the STROBE guidelines (Additional file 7).

\section{Study population, exposures and outcome}

The study population comprised very old patients ( $\geq 80$ years-old) admitted to the intensive care unit with CAP as main reason for admission for whom invasive or noninvasive ventilation was deemed necessary. We excluded ICU readmissions. The exposure of interest was whether the initial respiratory support was non-invasive or invasive mechanical ventilation in the first day of ICU admission. The group of patients who did not receive either NIV or IMV (no-MV) during the first day was followed as a "watchful waiting" comparability group to avoid selection bias in our sample, since conditioning on only NIV or IMV could lead to collider-stratification bias (16). The primary outcome was hospital mortality.

\section{Data collection and definitions}

We retrieved data from a prospectively collected multicenter ICU database (Epimed Monitor System ${ }^{\circledR}$, Epimed Solutions ${ }^{\circledR}$, Rio de Janeiro, Brazil), a cloud-based registry for ICU quality improvement in Brazil(17). Data of all admitted patients are entered in the system by a trained case manager nurse and regularly audited. Retrieved variables included demographics (age and sex), body mass index, admission SAPS 3 (18), 1st day sequential organ failure assessment (SOFA) score (19), previous functional status 
(6), comorbidities (all those from the Charlson comorbidity index) (20), 1st hour physiological data $\left(\mathrm{P}_{\mathrm{a}} \mathrm{O}_{2} / \mathrm{F}_{\mathrm{i}} \mathrm{O}_{2}\right.$ ratio, $\mathrm{P}_{\mathrm{a}} \mathrm{CO}_{2}$ and $\left.\mathrm{pH}\right)$, use of organ support in the 1 st hour, 1 st 24 hours and throughout ICU stay (vasopressors, renal replacement therapy, IMV, NIV), ICU and hospital length-of-stay and mortality, and palliative care decision within 24 hours of ICU admission. We calculated the Pneumonia severity index (PSI), the modified frailty index (MFI)(21) and whether the patients were septic or not (according to Sepsis 3.0 definitions) $(22,23)$ from available variables of the dataset.

\section{Data analysis}

Categorical variables are described as numbers and percentages. Quantitative variables are presented as means (standard deviations) or medians [25th percentile, 75th percentile] accordingly. Continuous variables were evaluated for normality with histograms and analyzed with t-tests when appropriate. Nonnormal continuous variables and discrete variables were analyzed with the Wilcoxon rank-sum test. Categorical variables were analyzed with the chi-squared test or the Fisher exact test, as appropriate.

The choice of the initial treatment strategy is associated with several clinical conditions. As recommended by Lederer et al., we chose the full set of potential confounding factors based on a directed acyclic graph (DAG), accounting for causal paths and avoiding mediators, open back-door paths and collider-bias (16) (Additional file 2, figure S1). We ran multivariable logistic regression models adjusting for potential confounders with different sets of covariates at a time: model 1: age and sex; model 2: model 1 plus body mass index (a proxy for malnutrition), COPD, heart failure, dementia and performance status; model 3: model 2 plus non-respiratory SOFA and admission source; model 4 (main model): model 3 plus respiratory variables $\left(\mathrm{P}_{\mathrm{a}} \mathrm{O}_{2} / \mathrm{F}_{\mathrm{i}} \mathrm{O}_{2}<150 \mathrm{mmHg}, \mathrm{pH}<7.3, \mathrm{P}_{\mathrm{a}} \mathrm{CO}_{2}>50 \mathrm{mmHg}\right)$. We explored robustness of the main model with four sensitivity analyses: 1) adding the SAPS 3 score in model 2, providing a different strategy to deal with severity and acuity variables spending less degrees of freedom;2) excluding patients in whom palliative care was ascertained in the first day of ICU admission; 3 ) analyzing only patients admitted directly from the emergency department; and 4) running the main model (model 4) in complete case analysis. We evaluated effect modification by adding an interaction term in model 4 (main model) for ad-hoc defined subgroups: COPD, heart failure, severe functional status impairment, non-respiratory SOFA $\geq 4, \mathrm{P}_{\mathrm{a}} \mathrm{O}_{2} / \mathrm{F}_{\mathrm{i}} \mathrm{O}_{2} \leq 150 \mathrm{mmHg}$ and acute respiratory acidosis $\left(\mathrm{pH}<7.3\right.$ and $\mathrm{P}_{\mathrm{a}} \mathrm{cO}_{2} \geq$ $50 \mathrm{mmHg}$ ). Cut-off values were based on standard values used in other studies and traditional indication for NIV (eg, acute respiratory acidosis).

We derived the marginal prediction from model 4 to illustrate the association between the initial strategy of ventilation and mortality in some scenarios. The marginal prediction represents the mortality predicted by the model if all patients in the cohort had received NIV or IMV in each scenario, while all other covariates are kept as observed (24). We explored scenarios that contrasted the magnitude of extra pulmonary organ dysfunction [low (0), intermediate (4) vs. high (8) non-respiratory SOFA score]; functional status impairment (severe vs. non-severe); and hypoxemia $\left(\mathrm{P}_{\mathrm{a}} \mathrm{O}_{2} / \mathrm{F}_{\mathrm{i}} \mathrm{O}_{2}\right.$ ratio $>150$ or $\leq$ $150 \mathrm{mmHg}$ ). Furthermore, in an as-treated analysis, we evaluated the outcomes of patients of the NIV 
group who were intubated within or after 24 hours of ICU admission, and calculated adjusted odds ratios, adjusting for as model 4.

We conducted multiple imputation to deal with missing data in covariates (25) (Additional file 1, supplemental methods). We assumed data to be missing at random and imputed 50 datasets using chained equations with predictive mean matching. We included in the imputation model the outcome and exposure variables, all variables considered for covariate adjustment, interactions terms and auxiliary variables (26). Further details of data missingness and the imputation model are described in the Additional file 1 , supplemental methods.

We considered a p-value $<0.05$ as statistically significant for all analyses. StataSE $\circledast$ version 14.2 was used for all analyses and the command mimrgns was used to generate marginal effects.

\section{Results}

6,318 very old patients were admitted to the ICUs from Jan, 2009, to December, 2012. 678 patients were admitted due to CAP (Additional file 3, Figure S2), out of which 369 presented with respiratory failure (NIV, 232 [63\%]; IMV, 137 [37\%]) (Figure 1). Overall, median age was 86 [83; 89] years and there was a higher proportion of female patients (55\%). $31 \%$ of patients were severely impaired, while $45 \%$ were frail according to the MFI. Median SOFA was $5.5[3 ; 8]$ and mean SAPS 3 was 68 (+/-14). Table 1 describes the main characteristics of the study groups: there were no differences regarding antecedent characteristics; however, the IMV group differed regarding admission source and acuity variables, with higher non-respiratory SOFA scores, higher SAPS 3 scores, lower $\mathrm{pH}$ and lower $\mathrm{P}_{\mathrm{a}} \mathrm{O}_{2} / \mathrm{F}_{\mathrm{i}} \mathrm{O}_{2}$ ratio (Table 1). Overall hospital mortality was 55\% (204/369): it ranged from $49 \%$ (114/232) in patients of the NIV group to $66 \%(90 / 137)$ for patients in the IMV group. Additional file 4, table S1 further presents the comparisons between survivors and decedents.

The primary outcome analysis results are presented in table 2 . When comparing NIV and IMV as the initial respiratory support strategy, the sequential adjustment suggested the association was largely confounded by acuity variables. Indeed, the crude odds ratio $(\mathrm{OR})$ was $0.50(95 \% \mathrm{Cl}, 0.33-0.78, \mathrm{p}=0.002)$, and subsequently $0.70(95 \% \mathrm{Cl}, 0.41-1.20, \mathrm{p}=0.196)$ for model 3 (antecedents plus non-respiratory SOFA) and $0.81(95 \% \mathrm{Cl}, 0.46-1.41, \mathrm{p}=0.452)$ for model 4 (model 3 plus oxygenation and alveolar ventilation variables).

We observed similar results in sensitivity analyses for the primary outcome comparing NIV vs. IMV (Additional file 5, Table S2): 1) adding SAPS 3 in the model yielded an adj OR of 0.77 (95\% Cl, 0.45-1.31, $\mathrm{p}=0.34$ ); 2 ) excluding patients with an early definition of palliative care (within 24 hours of ICU admission) yielded an adj $\mathrm{OR}$ of $0.78(95 \% \mathrm{Cl}, 0.44-1.38, \mathrm{p}=0.39) ; 3)$ analyzing only patients admitted directly from the emergency department yielded an ${ }_{\text {adj }} \mathrm{OR}$ of $\left.1.03(95 \% \mathrm{Cl}, 0.51-2.08, \mathrm{p}=0.94) ; 4\right)$ analyzing only patients with PSI scores $\geq$ IV/V yielded an ${ }_{\text {adj }} \mathrm{OR}$ of $0.83(95 \% \mathrm{Cl}, 0.47-1.46, \mathrm{p}=0.51)$; and 5) the complete case data analysis yielded an adj $\mathrm{OR}$ of $1.02(95 \% \mathrm{Cl}, 0.40-2.64, \mathrm{p}=0.96)$. 
In subgroup analyses (Figure 2), there was no evidence of effect modification for the association between NIV vs. IMV on hospital mortality regarding important antecedent characteristics - performance status, previous diagnosis of CHF and COPD - neither acute physiologic variables - non-respiratory SOFA $\geq 4$, acute respiratory acidosis and $\mathrm{P}_{\mathrm{a}} \mathrm{O}_{2} / \mathrm{F}_{\mathrm{i}} \mathrm{O}_{2}$ ratio $<150 \mathrm{mmHg}$.

Figure 3 presents the predicted probabilities of hospital mortality in each group across the representative values. We observed a small difference in predicted hospital mortality by the initial ventilator strategy. However, there was a sharp increase in predicted mortality for higher non-respiratory SOFA scores. Within each non-respiratory SOFA score group, $\mathrm{P}_{\mathrm{a}} \mathrm{O}_{2} / \mathrm{F}_{\mathrm{i}} \mathrm{O}_{2}$ ratio $\leq 150 \mathrm{mmHg}$ and, to a lesser extent, severe functional status impaired also changed the marginal probabilities of death.

In an as-treated analysis, 27 out of 232 patients (11.6\%) of the NIV group were intubated within 24 hours of ICU admission and 37 out of the remaining 205 (18\%) were intubated after 24 hours (Figure 1). Patients of the NIV group who did not need IMV during their ICU course had the lower odds of death (adj OR 0.52, 95\% Cl, 0.28-0.97, p = 0.039). By contrast, patients who were intubated after the first 24 hours of ICU admission had higher odds of death ( ${ }_{\text {adj }} \mathrm{OR} 3.22,95 \% \mathrm{Cl}, 1.21-8.55, \mathrm{p}=0.019$ ) (Additional file 6, table S3).

\section{Discussion}

\section{Main findings}

In this multicenter cohort study, NIV as the initial ventilatory strategy was not associated with lower hospital mortality among VOPs admitted to the ICU with CAP. We observed a significant degree of positive confounding, mainly explained by acuity variables included in the SOFA score. There was no strong evidence of effect modification regarding important subgroups of patients who usually benefit from NIV (COPD, heart failure) $(10,11)$ neither on those who usually have worse outcomes under NIV in this setting $\left(\mathrm{P}_{\mathrm{a}} \mathrm{O}_{2} / \mathrm{F}_{\mathrm{i}} \mathrm{O}_{2}<150\right.$, higher non-respiratory SOFA scores) (3). Results were robust to sensitivity analyses of the main model and the imputation model assumptions. Irrespective of the initial ventilatory strategy, mortality rates were high for patients who were ultimately intubated, especially in the context of high non-respiratory SOFA scores, low $\mathrm{P}_{\mathrm{a}} \mathrm{O}_{2} / \mathrm{F}_{\mathrm{i}} \mathrm{O}_{2}$ ratio and in patients who were intubated after the first 24 hours of ICU admission.

\section{Relationship with the literature}

The hospital mortality for VOPs admitted with CAP to the ICU is quite high. In our cohort, the overall hospital mortality was $55 \%$. In the United States, the 30-day mortality of elderly ( $\geq 65$ years-old) Medicare beneficiaries admitted with pneumonia to the ICU is of $36 \%$ (27), while for those who used NIV or IMV, 30 day mortality was $52.1 \%$ and $55.3 \%$, respectively (28). In the UK case mix program, data from the early 2000 's show a hospital mortality of 50\% regardless of age. In this context, we primarily hypothesized that a less invasive strategy would benefit this high mortality target population, but our results were neutral. 
One explanation is that the use of NIV in patients with high respiratory drive and high tidal volumes might be a matter of concern (29). Recent evidence suggests that self-inflicted lung injury may occur through many mechanisms and could be an issue if one decides not to intubate and allow the patient to have substantial spontaneous respiratory efforts (30). Finding the patient who would be harmed by spontaneous breathing is still a matter of debate, though, including those under IMV (31).

An alternative explanation to our findings is that the strategy of mechanical ventilation may not have an impact on the outcome whatsoever if used within reasonable clinical grounds and considering that NIV is frequently used as ceiling therapy. Valley et al., in a large retrospective cohort of elderly ( $\geq 65$ years) patients, showed that NIV was no better than IMV, with an absolute risk reduction in 30-day mortality of $0.7 \%(95 \% \mathrm{Cl},-13.8-12.4, \mathrm{p}=0.92)(28)$. Our results add to this literature in that we had more granular physiological data beyond ICD-9 codes and we could observe that acuity variables were the main confounders of this association and probably the main determinants of outcome. Although pointestimates did not differ much between NIV and IMV (Fig. 3), there was an evident gradient of increased mortality from the confounding variables.

Another concern is that studies assessing NIV in patients with pneumonia have yielded varying results ( 2 , $5,28,32$ ), suggesting that NIV could even be harmful if applied to patients with a higher burden of nonrespiratory organ dysfunctions or too hypoxemic $(3,4)$. Our subgroup analyses assessing effect modification did not suggest this was the case. Point estimates were not worrisome, except for patients with a $\mathrm{P}_{\mathrm{a}} \mathrm{O}_{2} / \mathrm{F}_{\mathrm{i}} \mathrm{O}_{2}$ ratio $\leq 150$, in whom the point estimate differed substantially showing increased harm in those who received NIV, although with a high degree of uncertainty. Although this is biologically plausible and has been shown to be a predictor of failure of NIV, any interpretation of these findings should be very cautious, given the usual low power of subgroup analyses.

Our results should also be interpreted accounting for a risk of misdiagnosis of pneumonia (33). Common explanations for misdiagnosis include both acute exacerbations of COPD or pulmonary edema from congestive heart failure, which may be difficult to differentiate from pneumonia at patient presentation. Although misdiagnosis could have a potential to bias our results, it would probably do so towards positive associations favoring NIV, which was not the case in our sample. Having said that, we believe this situation actually reflects usual clinical practice and may enhance generalizability of our findings (34).

\section{Implications for practice}

Our results suggest that a careful balance of benefits and harms of each strategy and the risks of NIV failure - and worse outcomes when in happens - should be weighed against patient's values and preferences to decide the best course of action. Clinicians should not avoid using NIV as an initial strategy of ventilation if it is used within reasonable clinical grounds, since there was no strong signal of harm from this strategy. Furthermore, NIV use as ceiling therapy should still be regarded as an alternative to IMV when treatment limitations are in place. By contrast, clinicians should not avoid offering IMV for VOPs admitted with pneumonia, especially early during their ICU course. Nevertheless, the prognostic 
implications of the need for IMV should be considered, especially later during ICU stay and when the burden of extra-pulmonary organ dysfunction is higher and functional impairment is severe.

\section{Strengths and limitations}

Our manuscript has some strengths. The multicenter nature of our study with $11 \mathrm{ICUs}$ from different hospitals and the real-world scenario with treatment limitations in place enhances the generalizability of our results. To account for the inherent risks of an observational study, we developed a causal DAG, which is an important step towards stronger inference and explicit selection of confounders (16), with sensitivity analyses to assumptions of the model being robust. Furthermore, we used multiple imputation to account for data missingness, a recommended approach that usually leads to less biased estimates while retaining higher statistical power $(25,26)$.

These results are also amenable to limitations. First, although collecting data from 11 ICUs over four years, we might have had low power to detect an association of benefit for NIV over IMV, considering we observed a protective point-estimate on our adjusted models; however, we had enough data points to include the main confounders in the regression model without overfitting the data. Second, we did not have data on pneumonia etiology and specific treatment, which might have an impact on outcome; nevertheless, we do not believe this would explicitly influence clinician's decision to use NIV or IMV and would therefore not be in the DAG. Third, hospital mortality may not be the best outcome to be assessed in this population, since long-term functional outcomes could be more valuable; unfortunately, we could not have access to such outcomes. Fourth, data on do-not-intubate orders were not explicitly available, although these are seldom used in Brazil and this could be partially captured when excluding patients under palliative care. Finally, we did not have measures of arterial blood gases neither ventilatory variables after the start of NIV, which could provide more mechanistic insights to explain our results (4, 29).

\section{Conclusions}

In a real-world sample of very old patients with community-acquired pneumonia admitted to the intensive care unit, non-invasive ventilation as the initial strategy was not associated with lower hospital mortality when compared to an invasive mechanical ventilation strategy, but there was no strong signal of harm from its use. The main confounders of this association were both the severity of respiratory dysfunction and of extra-respiratory organ failures.

\section{Abbreviation List}

CAP: Community-acquired pneumonia

CHF: Congestive heart failure

COPD: Chronic obstructive pulmonary disease 
DAG: Directed acyclic graph

ICU: Intensive care unit

IMV: Invasive mechanical ventilation

MFI: Modified frailty index

NIV: Non-invasive mechanical ventilation

OR: odds ratio

PS: performance status

adj OR: adjusted odds ratio

SOFA: Sequential organ failure assessment score

SAPS: Simplified acute physiologic score

VOP: Very old patients ( $\geq 80$ years-old

\section{Declarations}

Ethics approval and consent to participate: The Research and Ethics Committee of Hospital Pró-Cardíaco - the reference ethics committee designated by the National Research Ethics Committee - approved the retrospective analysis and publication of the data under the number 729.008 (CAAE: 33111214.3.0000.5533) and waived the need for informed consent.

Consent for publication: not applicable

Competing interests: the authors declare that there is no conflict of interest.

Financial Disclosures: none

Prior abstract presentation: this manuscript has been presented as a poster in Berlin, Citycube, at the $32^{\text {nd }}$ annual Congress, ESICM LIVES, 28 September - 2 October, 2019. 
Authors' contributions: BAMPB had full access to all of the data in the study and takes responsibility for the integrity of the data and the accuracy of the data analysis. BAMPB, MP and OTR contributed substantially to the study design, data analysis and interpretation, and the writing of the manuscript.

\section{Acknowledgements}

We would like to thank Leandro Utino Taniguchi, Pedro Caruso and Heraldo Possolo de Souza for their comments on a previous version of this manuscript. We would also like to thank Danilo Teixeira Noritomi for his support to start this project.

\section{Availability of data and materials}

The datasets generated and analyzed are not publicly available due to patient privacy considerations, but are available from the corresponding author on reasonable request.

\section{References}

1. Heyland D, Cook D, Bagshaw SM, Garland A, Stelfox HT, Mehta S, et al. The Very Elderly Admitted to ICU: A Quality Finish? Critical care medicine. 2015;43(7):1352-60.

2. Stefan MS, Priya A, Pekow PS, Lagu T, Steingrub JS, Hill NS, et al. The comparative effectiveness of noninvasive and invasive ventilation in patients with pneumonia. Journal of critical care. 2018;43:190-6.

3. Antonelli M, Conti G, Moro ML, Esquinas A, Gonzalez-Diaz G, Confalonieri M, et al. Predictors of failure of noninvasive positive pressure ventilation in patients with acute hypoxemic respiratory failure: a multi-center study. Intensive care medicine. 2001;27(11):1718-28.

4. Al-Rajhi A, Murad A, Li PZ, Shahin J. Outcomes and predictors of failure of non-invasive ventilation in patients with community acquired pneumonia in the ED. Am J Emerg Med. 2018;36(3):347-51.

5. Murad A, Li PZ, Dial S, Shahin J. The role of noninvasive positive pressure ventilation in communityacquired pneumonia. Journal of critical care. 2015;30(1):49-54.

6. Zampieri FG, Bozza FA, Moralez GM, Mazza DD, Scotti AV, Santino MS, et al. The effects of performance status one week before hospital admission on the outcomes of critically ill patients. Intensive care medicine. 2017;43(1):39-47.

7. Zampieri FG, Colombari F. The impact of performance status and comorbidities on the short-term prognosis of very elderly patients admitted to the ICU. BMC Anesthesiol. 2014;14:59. 
8. Heyland DK, Garland A, Bagshaw SM, Cook D, Rockwood K, Stelfox HT, et al. Recovery after critical illness in patients aged 80 years or older: a multi-center prospective observational cohort study. Intensive care medicine. 2015;41(11):1911-20.

9. Marik PE. Management of the critically ill geriatric patient. Critical care medicine. 2006;34(9 Suppl):S176-82.

10. Berbenetz N, Wang Y, Brown J, Godfrey C, Ahmad M, Vital FM, et al. Non-invasive positive pressure ventilation (CPAP or bilevel NPPV) for cardiogenic pulmonary oedema. Cochrane Database Syst Rev. 2019;4:CD005351.

11. Osadnik CR, Tee VS, Carson-Chahhoud KV, Picot J, Wedzicha JA, Smith BJ. Non-invasive ventilation for the management of acute hypercapnic respiratory failure due to exacerbation of chronic obstructive pulmonary disease. Cochrane Database Syst Rev. 2017;7:CD004104.

12. Garrouste-Orgeas M, Tabah A, Vesin A, Philippart F, Kpodji A, Bruel C, et al. The ETHICA study (part II): simulation study of determinants and variability of ICU physician decisions in patients aged 80 or over. Intensive care medicine. 2013;39(9):1574-83.

13. Philippart F, Vesin A, Bruel C, Kpodji A, Durand-Gasselin B, Garcon P, et al. The ETHICA study (part I): elderly's thoughts about intensive care unit admission for life-sustaining treatments. Intensive care medicine. 2013;39(9):1565-73.

14. Wilson ME, Majzoub AM, Dobler CC, Curtis JR, Nayfeh T, Thorsteinsdottir B, et al. Noninvasive Ventilation in Patients With Do-Not-Intubate and Comfort-Measures-Only Orders: A Systematic Review and Meta-Analysis. Critical care medicine. 2018;46(8):1209-16.

15. Vink EE, Azoulay E, Caplan A, Kompanje EJO, Bakker J. Time-limited trial of intensive care treatment: an overview of current literature. Intensive care medicine. 2018;44(9):1369-77.

16. Lederer DJ, Bell SC, Branson RD, Chalmers JD, Marshall R, Maslove DM, et al. Control of Confounding and Reporting of Results in Causal Inference Studies. Guidance for Authors from Editors of Respiratory, Sleep, and Critical Care Journals. Ann Am Thorac Soc. 2019;16(1):22-8.

17. Zampieri FG, Soares M, Borges LP, Salluh JIF, Ranzani OT. The Epimed Monitor ICU Database(R): a cloud-based national registry for adult intensive care unit patients in Brazil. Rev Bras Ter Intensiva. 2017;29(4):418-26.

18. Moreno RP, Metnitz PG, Almeida E, Jordan B, Bauer P, Campos RA, et al. SAPS 3--From evaluation of the patient to evaluation of the intensive care unit. Part 2: Development of a prognostic model for hospital mortality at ICU admission. Intensive care medicine. 2005;31(10):1345-55.

19. Vincent JL, Moreno R, Takala J, Willatts S, De Mendonca A, Bruining H, et al. The SOFA (Sepsisrelated Organ Failure Assessment) score to describe organ dysfunction/failure. On behalf of the Working Group on Sepsis-Related Problems of the European Society of Intensive Care Medicine. Intensive care medicine. 1996;22(7):707-10.

20. Charlson ME, Pompei P, Ales KL, MacKenzie CR. A new method of classifying prognostic comorbidity in longitudinal studies: development and validation. J Chronic Dis. 1987;40(5):373-83. 
21. Zampieri FG, Iwashyna TJ, Viglianti EM, Taniguchi LU, Viana WN, Costa R, et al. Association of frailty with short-term outcomes, organ support and resource use in critically ill patients. Intensive care medicine. 2018;44(9):1512-20.

22. Besen B, Romano TG, Nassar AP, Jr., Taniguchi LU, Azevedo LCP, Mendes PV, et al. Sepsis-3 definitions predict ICU mortality in a low-middle-income country. Ann Intensive Care. 2016;6(1):107.

23. Singer M, Deutschman CS, Seymour CW, Shankar-Hari M, Annane D, Bauer M, et al. The Third International Consensus Definitions for Sepsis and Septic Shock (Sepsis-3). JAMA : the journal of the American Medical Association. 2016;315(8):801-10.

24. Norton EC, Dowd BE, Maciejewski ML. Marginal Effects-Quantifying the Effect of Changes in Risk Factors in Logistic Regression Models. JAMA : the journal of the American Medical Association. 2019;321(13):1304-5.

25. Vesin A, Azoulay E, Ruckly S, Vignoud L, Rusinova K, Benoit D, et al. Reporting and handling missing values in clinical studies in intensive care units. Intensive care medicine. 2013;39(8):1396-404.

26. White IR, Royston P, Wood AM. Multiple imputation using chained equations: Issues and guidance for practice. Stat Med. 2011;30(4):377-99.

27. Valley TS, Sjoding MW, Ryan AM, Iwashyna TJ, Cooke CR. Association of Intensive Care Unit Admission With Mortality Among Older Patients With Pneumonia. JAMA : the journal of the American Medical Association. 2015;314(12):1272-9.

28. Valley TS, Walkey AJ, Lindenauer PK, Wiener RS, Cooke CR. Association Between Noninvasive Ventilation and Mortality Among Older Patients With Pneumonia. Critical care medicine. 2017;45(3):e246-e54.

29. Carteaux G, Millan-Guilarte T, De Prost N, Razazi K, Abid S, Thille AW, et al. Failure of Noninvasive Ventilation for De Novo Acute Hypoxemic Respiratory Failure: Role of Tidal Volume. Critical care medicine. 2016;44(2):282-90.

30. Yoshida T, Fujino Y, Amato MB, Kavanagh BP. Fifty Years of Research in ARDS. Spontaneous Breathing during Mechanical Ventilation. Risks, Mechanisms, and Management. American journal of respiratory and critical care medicine. 2017;195(8):985-92.

31. van Haren F, Pham T, Brochard L, Bellani G, Laffey J, Dres M, et al. Spontaneous Breathing in Early Acute Respiratory Distress Syndrome: Insights From the Large Observational Study to UNderstand the Global Impact of Severe Acute Respiratory FailurE Study. Critical care medicine. 2019;47(2):22938.

32. Carrillo A, Gonzalez-Diaz G, Ferrer M, Martinez-Quintana ME, Lopez-Martinez A, Llamas N, et al. Noninvasive ventilation in community-acquired pneumonia and severe acute respiratory failure. Intensive care medicine. 2012;38(3):458-66.

33. Daniel P, Bewick T, Welham S, McKeever TM, Lim WS, British Thoracic S. Adults miscoded and misdiagnosed as having pneumonia: results from the British Thoracic Society pneumonia audit. Thorax. 2017;72(4):376-9. 
34. Klein Klouwenberg PM, Cremer OL, van Vught LA, Ong DS, Frencken JF, Schultz MJ, et al. Likelihood of infection in patients with presumed sepsis at the time of intensive care unit admission: a cohort study. Critical care. 2015;19:319.

\section{Additional File Information}

\section{Additional file 1:}

Supplemental methods (PDF)

\section{Additional file 2:}

Figure S1: Directed acyclic graph (PDF)

\section{Additional file 3:}

Figure S2: Study sample flowchart (PDF)

\section{Additional file 4:}

Table S1: Characteristics of survivors and deceased patients (PDF)

\section{Additional file 5:}

Table S2: Sensitivity analyses for the primary outcome (PDF)

\section{Additional file 6:}

Table S3: As-treated analysis of each group compared to the invasive mechanical ventilation group (PDF)

\section{Additional file 7:}

STROBE Statement (PDF)

\section{Tables}

Table 1 - Patient characteristics at intensive care unit admission 


\begin{tabular}{|c|c|c|c|c|}
\hline Variable & $\begin{array}{l}\text { All patients } \\
\mathrm{N}=369\end{array}$ & $\begin{array}{l}\mathrm{NIV}^{\mathrm{a}} \\
\mathrm{N}=232\end{array}$ & $\begin{array}{l}\mathrm{IMV} \mathrm{b} \\
\mathrm{N}=137\end{array}$ & p-value \\
\hline Age, years & $86[83 ; 89]$ & $87[83 ; 90]$ & $86[82 ; 89]$ & 0.123 \\
\hline Male, n (\%) & $167(45.3 \%)$ & $101(43.5 \%)$ & $66(48.2 \%)$ & 0.387 \\
\hline Body mass index $<23 \mathrm{Kg} / \mathrm{m}^{2}$ & $\begin{array}{l}100 / 252 \\
(39.7 \%)\end{array}$ & $\begin{array}{l}55 / 154 \\
(35.7 \%)\end{array}$ & $45 / 98(45.9 \%)$ & 0.107 \\
\hline Charlson comorbidity index & $2[1 ; 3]$ & $2[1 ; 3]$ & $2[1 ; 3]$ & 0.91 \\
\hline \multicolumn{5}{|l|}{ Comorbidities } \\
\hline Hypertension & $191(51.8 \%)$ & $123(53 \%)$ & $68(49.6 \%)$ & 0.53 \\
\hline Diabetes & $103(27.9 \%)$ & $60(25.9 \%)$ & $43(31.4 \%)$ & 0.25 \\
\hline Heart failure & $69(18.7 \%)$ & $48(20.7 \%)$ & $21(15.3 \%)$ & 0.202 \\
\hline$C O P D^{\mathrm{c}}$ & $52(14.1 \%)$ & $28(12.1 \%)$ & $24(17.5 \%)$ & 0.146 \\
\hline$C K D^{\mathrm{d}}$ & $46(12.5 \%)$ & $32(13.8 \%)$ & $14(10.2 \%)$ & 0.32 \\
\hline Long-term dialysis & $7(1.9 \%)$ & $3(1.3 \%)$ & $4(2.9 \%)$ & 0.27 \\
\hline Cirrhosis & $2(0.5 \%)$ & $2(0.9 \%)$ & 0 & 0.53 \\
\hline Dementia & $104(28.2 \%)$ & $65(28 \%)$ & $39(28.5 \%)$ & 0.93 \\
\hline Cancer & $35(9.5 \%)$ & $23(9.9 \%)$ & $12(8.8 \%)$ & 0.71 \\
\hline $\begin{array}{l}\text { Performance status } \\
\text { impairment }\end{array}$ & & & & 0.434 \\
\hline Absent/Minor & $118(32 \%)$ & $70(30.2 \%)$ & $48(35 \%)$ & \\
\hline Moderate & $136(36.9 \%)$ & $91(39.2 \%)$ & $45(32.9 \%)$ & \\
\hline Severe & 115 (31.2\%) & $71(30.6 \%)$ & 44 (32.1\%) & \\
\hline Modified frailty index & & & & 0.985 \\
\hline Non-frail $\left(\mathrm{MFI}^{\mathrm{e}}=0\right)$ & $27(7.3 \%)$ & $17(7.3 \%)$ & $10(7.3 \%)$ & \\
\hline Pre-frail $\left(\mathrm{MFI}^{\mathrm{e}}=1-2\right)$ & $176(47.7 \%)$ & $110(47.4 \%)$ & $66(48.2 \%)$ & \\
\hline Frail $\left(\mathrm{MFI}^{\mathrm{e}} \geq 3\right.$ ) & $166(45 \%)$ & 105 (45.3\%) & $61(44.5 \%)$ & \\
\hline $\mathrm{PSI}^{\mathrm{f}} \mathrm{IV} / \mathrm{V}$ & $340(92.1 \%)$ & $205(88.4 \%)$ & 135 (98.5\%) & $\begin{array}{c}< \\
0.001\end{array}$ \\
\hline Sepsis & $287(79.7 \%)$ & $163(71.5 \%)$ & 124 (93.9\%) & $\stackrel{<}{0.001}$ \\
\hline SAPS $3^{\mathrm{g}}$ & $67.7(14)$ & $62.6(11)$ & $76.5(14.2)$ & $\begin{array}{c}< \\
0.001\end{array}$ \\
\hline SOFA $h$ & $5.5[3 ; 8]$ & $4[2 ; 7]$ & $8[6 ; 11]$ & $\begin{array}{c}< \\
0.001\end{array}$ \\
\hline Non-respiratory SOFA ${ }^{h}$ & $4[2 ; 7]$ & $3[1 ; 6]$ & $7[4 ; 9]$ & 0.001 \\
\hline${ }_{h}$ Non-respiratory SOFA $\geq 4$ & 193 (57.1\%) & $\begin{array}{l}96 / 217 \\
(44.2 \%)\end{array}$ & $\begin{array}{l}97 / 121 \\
(80.2 \%)\end{array}$ & 0.001 \\
\hline \multicolumn{5}{|l|}{ Arterial blood gases } \\
\hline$p H<7.3$ & $62 / 241(25.7 \%)$ & $\begin{array}{c}23 / 129 \\
(17.8 \%)\end{array}$ & $\begin{array}{c}39 / 112 \\
(34.8 \%)\end{array}$ & 0.003 \\
\hline$P_{a} o_{2} / F_{i} o_{2} \leq 150$ & $64 / 208(30.8 \%)$ & $\begin{array}{l}21 / 102 \\
(20.6 \%)\end{array}$ & $\begin{array}{l}43 / 106 \\
(40.6 \%)\end{array}$ & 0.002 \\
\hline Acute respiratory acidosis & $39 / 241(16.2 \%)$ & $\begin{array}{c}15 / 129 \\
(11.6 \%)\end{array}$ & $\begin{array}{l}24 / 112 \\
(21.4 \%)\end{array}$ & 0.039 \\
\hline Palliative care within $24 \mathrm{~h}$ & $25(6.8 \%)$ & $19(8.2 \%)$ & $6(4.4 \%)$ & 0.20 \\
\hline Admission source & & & & 0.015 \\
\hline Emergency department & $225(61 \%)$ & $143(61.6 \%)$ & $82(59.9 \%)$ & \\
\hline Ward & $89(24.1 \%)$ & $64(27.6 \%)$ & $25(18.3 \%)$ & \\
\hline Other hospital & $43(11.7 \%)$ & $19(8.2 \%)$ & $24(17.5 \%)$ & \\
\hline
\end{tabular}




\begin{tabular}{|c|c|c|c|c|}
\hline Other & $12(3.2 \%)$ & $6(2.6 \%)$ & $6(4.4 \%)$ & \\
\hline \multicolumn{5}{|l|}{ Other organ support } \\
\hline Vasoactive drugs (24h) & $123(33.3 \%)$ & $31(13.4 \%)$ & $92(67.2 \%)$ & $\begin{array}{c}< \\
0.001\end{array}$ \\
\hline Vasoactive drugs (any) & $167(45.3 \%)$ & $62(26.7 \%)$ & $105(76.6 \%)$ & $\begin{array}{c}< \\
0.001\end{array}$ \\
\hline $\mathrm{RRT}^{\mathrm{i}}(24 \mathrm{~h})$ & $5(1.4 \%)$ & $3(1.3 \%)$ & $2(1.5 \%)$ & $>0.99$ \\
\hline $\mathrm{RRT}^{\mathrm{i}}$ (any) & $22(6 \%)$ & $11(4.7 \%)$ & $11(8 \%)$ & 0.198 \\
\hline
\end{tabular}

a Non-invasive mechanical ventilation; ${ }^{\mathrm{b}}$ Invasive mechanical ventilation; ${ }^{\mathrm{c}}$ Chronic obstructive pulmonary disease; ${ }^{\mathrm{d}}$ Chronic kidney disease; ${ }^{\mathrm{e}}$ Modified frailty index; ${ }^{\mathrm{f}}$ Pneumonia severity index; ${ }^{\mathrm{g}}$ Simplified acute physiologic score $3^{\text {rd }}$ version; ${ }^{\text {h }}$ Sequential organ failure assessment in the first 24 hours of ICU admission; ${ }^{i}$ Renal replacement therapy

\begin{tabular}{lcc}
\hline \multicolumn{2}{l}{ Table 2 - Crude and adjusted odds ratios for hospital mortality between groups } \\
\hline & OR $(95 \%$ CI $)$ & p-value \\
\hline Crude analysis & $0.50(0.33-0.78)$ & 0.002 \\
Model 1 & $0.47(0.30-0.74)$ & 0.001 \\
\hline Model 2 $^{\mathrm{b}}$ & $0.45(0.29-0.72)$ & 0.001 \\
Model 3 $^{\mathrm{c}}$ & $0.70(0.41-1.20)$ & 0.196 \\
Model 4 $^{\mathrm{d}}$ & $0.81(0.46-1.41)$ & 0.452 \\
\hline
\end{tabular}

a Model 1: adjusting for age and sex

b Model 2: adjusting for model $1+$ antecedent characteristics (body mass index + comorbidities + functional status)

${ }^{\mathrm{C}}$ Model 3: adjusting for model $2+$ non-respiratory SOFA + source

$\mathrm{d}$ Model 4: adjusting for model $3+\mathrm{ABG}$ variables $\left(\mathrm{P}_{\mathrm{a}} \mathrm{O}_{2} / \mathrm{FiO}_{2}\right.$ ratio, $\left.\mathrm{pH}, \mathrm{Pco}_{2}\right)$

* Invasive mechanical ventilation is the referent group

\section{Figures}




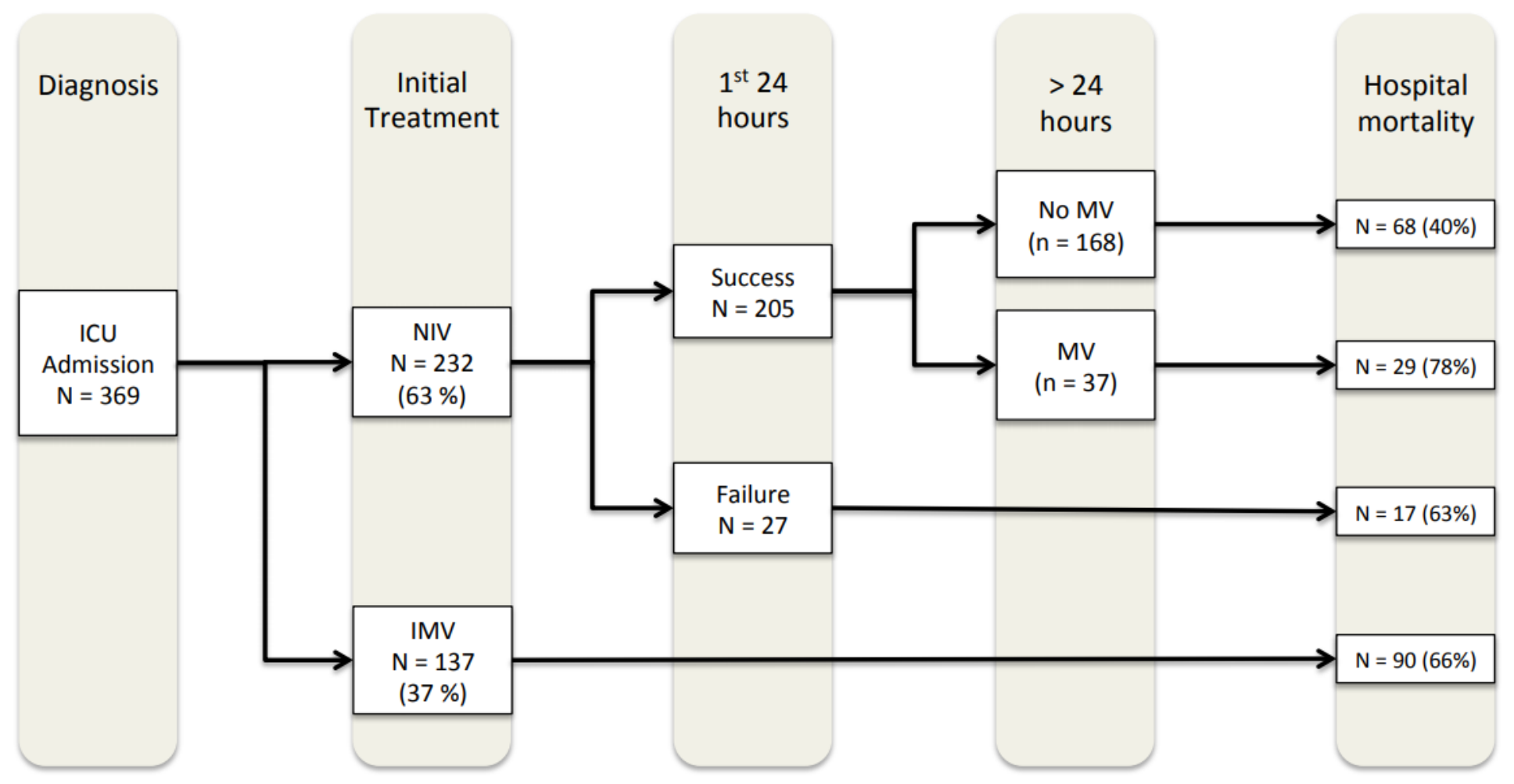

\section{Figure 1}

Flowchart of study participants from intensive care unit admission until the outcome (hospital death or discharge) according to the ventilation strategy ICU: Intensive care unit; (I)MV: Invasive Mechanical ventilation; NIV: Non-invasive ventilation; Success/Failure: need for invasive mechanical ventilation within 24 hours of ICU admission. 


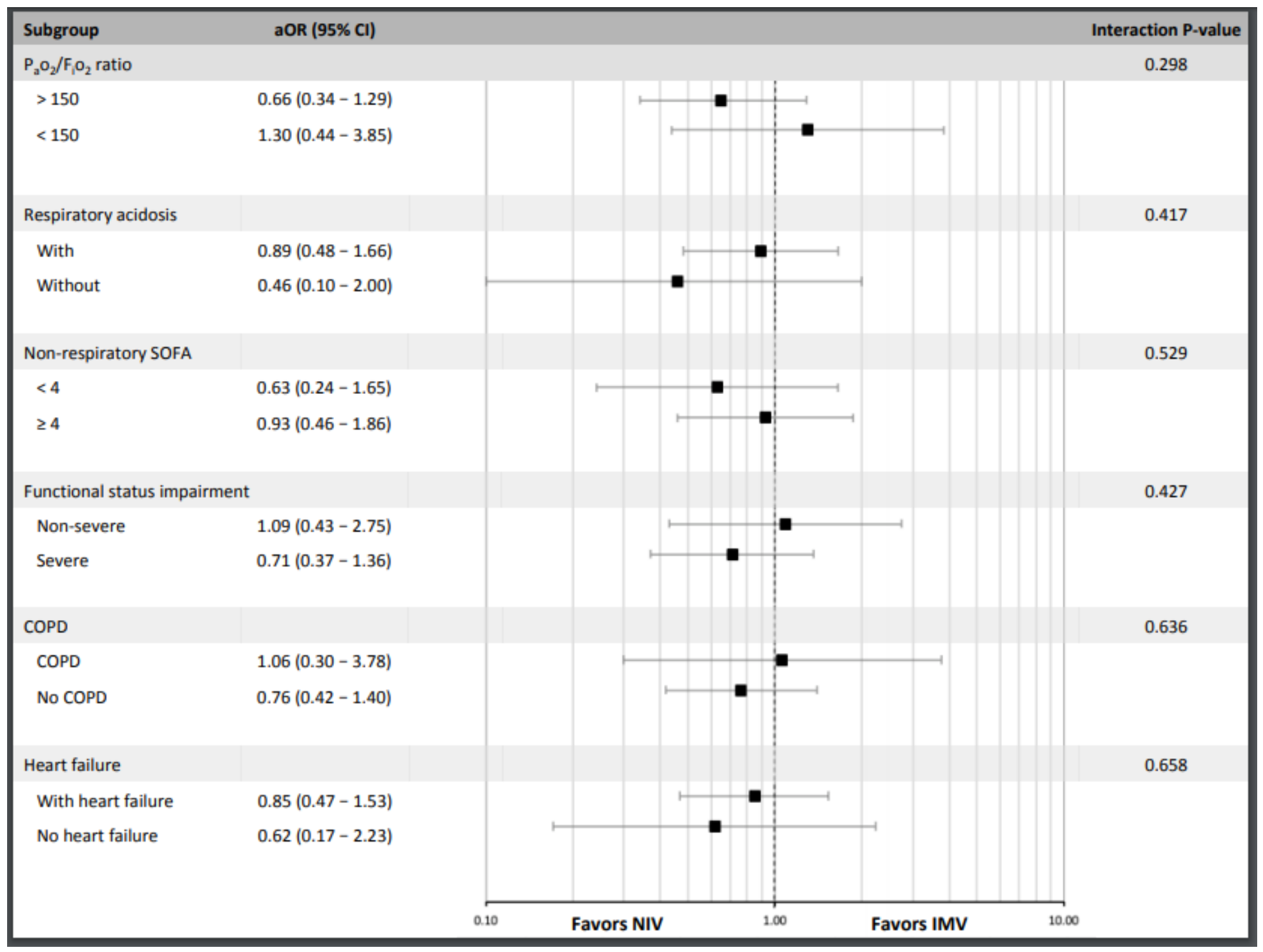

\section{Figure 2}

Subgroup analysis of the effect of non-invasive ventilation vs. invasive mechanical ventilation on hospital mortality The $x$-axis represents the odds ratio for the comparison of non-invasive ventilation (NIV) vs. invasive mechanical ventilation (IMV) according to the analyzed subgroup. SOFA: Sequential organ failure assessment; COPD: Chronic obstructive pulmonary disease 


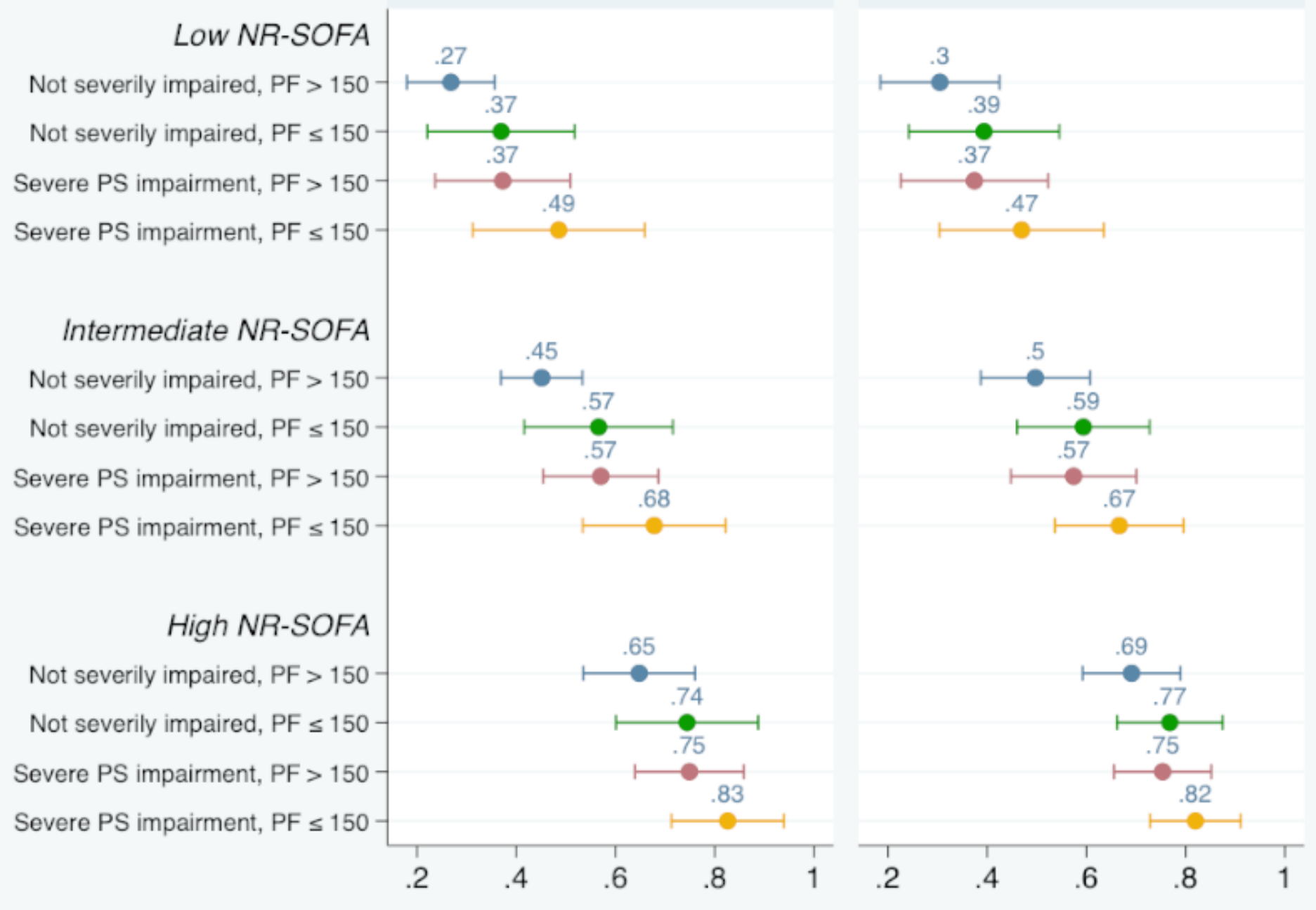

\section{Figure 3}

Marginal probability of hospital mortality according to the initial strategy of mechanical ventilation and three major patient characteristics The $\mathrm{x}$-axis represents the probability of the outcome (hospital mortality) according to representative values of covariates, stratified according to the initial strategy of mechanical ventilation (non-invasive ventilation or invasive mechanical ventilation). For example, a patient who was initially under non-invasive ventilation, with an intermediate NR-SOFA, not severely impaired and with a Pao2/Fio2 ratio $\leq 150$ had a predicted probability of hospital mortality of $57 \%$. MV: mechanical ventilation; PF: Pao2/Fio2 ratio; PS: performance status; NR-SOFA: non-respiratory sequential organ failure assessment; Low-NR SOFA represents a value of 0 ; intermediate represents a value of 4; high represents a value of 8

\section{Supplementary Files}

This is a list of supplementary files associated with this preprint. Click to download.

- Additionalfile2Figures1.pdf 
- Additionalfile4Tables1.pdf

- Additionalfile6Tables3.pdf

- Additionalfile3Figures2.pdf

- Additionalfile7STROBEStatement.pdf

- Additionalfile1Supplementalmethods.pdf

- Additionalfile5Tables2.pdf 